\title{
Forms and methods of remote control of university students learning
}

\author{
Evgeniy Leonovich ${ }^{1 *}$, Marina Romanova ${ }^{1}$, Nina Khodakova $^{1}$, Anna Kalinchenko ${ }^{1}$, and \\ Dmitry Kalinchenko ${ }^{1}$ \\ ${ }^{1}$ Moscow City University, Institute of Pedagogy and Psychology of Education, Moscow, Russia
}

\begin{abstract}
This article discuses searching for forms and methods of remote control of learning of university students. The importance of this problem is stipulated by the necessity to organize distance learning in existing environment and wide education opportunities supported by electronic resources and their purposeful use. The formulated hypothesis states that their controlled use would allow to perform efficient control of learning at all stages of training. In order to confirm this hypothesis, the authors presented the results of activities of university teachers aimed at searching for forms and methods of remote control of students' learning. This article discusses managerial, cognitive, and axiological aspects of remote control. The trends of searching for efficient approaches to solve the formulated problem are analyzed. Opportunity to apply network interaction of students upon distance learning is considered as well as control of formation of professional activities upon remote access. The network interaction acts as a mechanism of selection of forms and methods of distance control, such as discussion of assignment in remote access using electronic resources, online presentation of photos and videos required for joint work of all group students, presentation of results of assignment execution on interactive whiteboard of internet platform, joint work using electronic resource to create project. The control processes of distance learning are very important in professional training. The control procedures allow simultaneous correction during learning at each stage, promote searching and implementation of new methods of learning. Application of the described forms and methods allows providing efficient control of learning.
\end{abstract}

Keywords: learning of university students, distance learning, forms and methods of control, network interaction.

\section{Introduction}

Modern society has created global information system, which became a required resource in all spheres of production and leisure time. Information steams are accumulated in databases and are inherent portion of education content. The education information has been transformed and acquired more expanded essence. Any studied process or

\footnotetext{
* Corresponding author: leonovichen@mgpu.ru
} 
phenomenon should be thoroughly analyzed with consideration for various points of view available in information environment. Following the content of training, approaches to it should be changed and, what is more important, to its control. It is the control procedures that allow to correct in time both the content of training and quality of its assimilation.

In foreign and Russian pedagogics, serious attention is paid to digital learning. In the digital learning, one of the main forms is distance learning, which is included in the practices of all learning stages [1-5].

However, communication in remote access increases the need to search and describe mechanisms for identifying facts of learning or difficulties in understanding learning material at intermediate stages, as well as for timely correction of learning, if required. Teachers should determine methods of arrangement of control for distance learning of university students, which would allow to obtain in time the information about scope and consistency of knowledge [6].

The distance learning is characterized by wide opportunities to apply electronic educational resources, which allow to transfer online assignments, to perform quick exchange with messages in chats, to use the space of electronic platform as interactive whiteboard, using which it is possible to correct, to comment, to express attitude to events by signs and symbols, etc.

The most complicated and meaningful problem is to find and to apply the mechanisms of distance learning, allowing to detect potential capabilities of students in understanding logics of studied science, their capabilities to analyze the learning material. This requires for determination of forms and methods of learning remote control, analyzed in this work.

\section{Methods}

The work applied both theoretical methods, such as analysis of scientific publications, analysis and generalization of working experience with junior pupils regarding the formulated problem, design of learning, and experimental methods, which allowed to establish trends in variation of didactic factors upon organization of transfer of learning information and its analysis and use.

Sociologists from Western Europe and North America (D. Bell, M. Castells, M. McLuhan, E. Toffler, and others) report that information became the main (sometimes the only) source of not only spiritual but also material wealth, which significantly increased the time for its search and reduced the time for its analysis, increased priority of its use in already structured and simplified form [7-9].

In this regard, the information stream influencing students has become more probabilistic. The scope of electronic resources assumes fragmentary selection of learning texts aiming at their rapid use for causal execution of control task from the teacher. These provisions are confirmed by analysis of pedagogical practice in university.

It is possible to mention several aspects of application of remote-control mechanisms, allowing to substantiate selection of forms and methods used in this process.

\subsection{Managerial aspect}

While performing distance control of learning, the most important is precise determination of its objectives and targets $[10,11]$. It is required to distinguish intermediate control of knowledge quality, control of learning intensity and regularity, control of content, control of cognitive activity, correcting control, final control, etc. [12]. Electronic resources allow to observe the digital trace of learning, which provides accurate data on learning intensity and regularity recorded on learning platforms. However, the issues related with cognitive 
activity of students require for development of forms and methods reflecting their level upon execution of specially developed assignments. Management of creative activity assumes organization of project execution, solution of nonstandard and logical tasks, classes with elements of network interaction aimed at joint search for answers. The electronic resources should contain sets of assignments to be used by students, requiring for presentation of innovation solutions to professional situations.

\subsection{Cognitive aspect}

This aspect is related with development of methods and selection of control forms upon execution of professional tasks by students. The network interaction was the most efficient: the students participated in active discussion in chats, exchanged information using audio and video communication, uploaded intermediate solutions to portals. Cognitive control methods are development of didactic situations promoting cognitive activities. They can be either reproductive, when each student executes his assignment using pattern and the students of one group obtain complete solution by algorithm using their intermediate results, and productive, i.e. related with execution of project and its presentation in the frames of intermediate control.

\subsection{Axiological aspect}

Formation of motivating and evaluating attitude of students to control procedures is important in distance learning. Demonstrating their attitude to discussed processes or phenomena, students initiate discussion, which expresses cognitive activity. In digital environment, an occurring situation can be assessed by a sign or a symbol (like). Rapid, sometimes affective, assessment of occurring situation during classes allows to response timely to requests from students and to correct work. This strategy is important to eliminate difficulties in distance learning [13]. Educational character of network interaction allows to provide the required insights into methods to increase motivation to learning during its execution in virtual environment.

\section{Results}

The experiments on application of forms and tools of distance control during forced distance learning in the spring of 2020 demonstrated that the professional training was performed with opportunity to form the preset professional competences. However, it should be understood that selection of forms and tools of distance learning control depends on technical competence of teachers. This problem can be solved by organization of professional development courses in the field of IT-technologies.

The teachers successfully controlled the distance learning using such forms and methods as discussion of assignment in remote access using electronic resources, online demonstration of photos and video materials required for joint work of all group students, uploading results of assignment execution to interactive whiteboard of internet platform, joint work using electronic resources to develop project. In students' group, digital environment was created for efficient interaction upon execution of assignments, the students cooperated for solving problems and recorded the obtained results on electronic platforms.

Thus, it could be stated that the network interaction became the mechanism, which provided timely control of learning. 


\section{Discussion}

The necessity of wide discussion of innovations is confirmed in experimental works [14]. Therefore, the authors invited teachers, who actively used online learning, to discuss the forms and tools of distance control. In addition, the authors performed surveying of students about distance learning. It was detected that the highest activity upon online learning was demonstrated by highly motivated students, who with any form of arrangement of their activities showed cognitive interest and were involved in the process. An obvious advantage was the increased attending of online classes, which could be attributed to the opportunity to join the distance studies using any device with Internet connection being anywhere. The network interaction aiming at arrangement of distance control promoted significantly the cognitive activity of students. Following the conclusions by Y.A. Alisov [15], the authors confirmed the opportunity to form designing activities of students, conscious choice of necessary and sufficient professional skills.

\section{Conclusion}

Remote control of learning in universities can be considered as a technology allowing efficient promotion of educational and cognitive activities of students in the frames of digital learning. The mechanism of network interaction is based on theoretical data in the field of education management, axiology, studies in the field of cognitive development of students. The presented developments allow not only implementing control procedures but also activating the process of distance learning.

\section{References}

1. G.V. Kuritsyna, Mezhdunarodnyy zhurnal eksperimental'nogo obrazovaniya, 8(3), 17$21(2014)$

2. Y.Y. Petryaeva, Uspekhi sovremennoy nauki i obrazovaniya, 1(2), 51-59 (2017)

3. Ch.B. Hodges, S. Moore, B.B. Lockee, T. Trust, M.A. Bond, Educause Review (2020). Accessed on: December 16, 2020. [Online]. Available:

https://er.educause.edu/articles/2020/3/the-difference-between-emergency-remoteteaching-and-online-learning

4. L. Kyungmee, Distance Education, 41(2), 186-200 (2020). https://doi.org/10.1080/01587919.2020.1757404

5. T. Levkova, R. Bazhenov, S. Solina, M. Romanova, S. Chebarykova, Ethic characteristics of decision-making by students in situation of moral choice, in The European Proceedings of Social and Behavioural Sciences, SCTCMG, 1-3 November 2018, Groznyi, Russia (2019). https://dx.doi.org/10.15405/epsbs.2019.03.02.74

6. A.I. Savenkov, A.S. Lvova, O.A. Lyubchenko, Pedagogika, 1, 83-88 (2017)

7. M. Castells, The Rise of the Network Society (Wiley-Blackwell, Cambridge, 2000)

8. M. McLuhan, Q. Fiore, War and Peace in the Global Village (Gingko Press, Berkeley, 2001)

9. M. Castells, The Information Age: Economy, Society and Culture, Volume I, The Rise of the Network Society (Wiley-Blackwell, Cambridge, 2000)

10. Y.A. Alisov, Psikhologo-pedagogicheskiy zhurnal Gaudeamus, 2(26), 56-63 (2015)

11. A.I. Adamsky, Y.Y. Petryaeva, Obrazovatel'naya politika, 1(71), 11-21 (2016) 
12. A.I. Savenkov, Y.A. Alisov, A.S. Lvova, Vestnik Moskovskogo pedagogicheskogo universiteta. Seriya: Pedagogika i Psykhologiya, 1(31), 18-26 (2015)

13. I.V. Vachkov, S.N. Vachkova, M.V. Voropaev, Pedagogicheskaya nauka i obrazovaniye, 24(3), 19-31 (2019)

14. I.M. Remorenko, S.N. Vachkova, K.A. Barannikov, Vestnik Immanuel Kant Baltic Federal University, 5, 40-47 (2015)

15. Y.A. Alisov, To the problem of designing a multimodal educational environment: search for methodological and technological foundations, in Conference of Pedagogical education: challenges of the XXI century. Collection of scientific papers of the All-Russian scientific-practical conference dedicated to the memory of Academician V.A. Slastenin, Novosibirsk State Pedagogical University, 26-27 September 2019, Novosibirsk, Russia (2019)

16. M.F. Rice, P.R. Lowenthal, X. Woodley, Distance Education, 41(3), 319-325 (2020). https://doi.org/10.1080/01587919.2020.1790091 